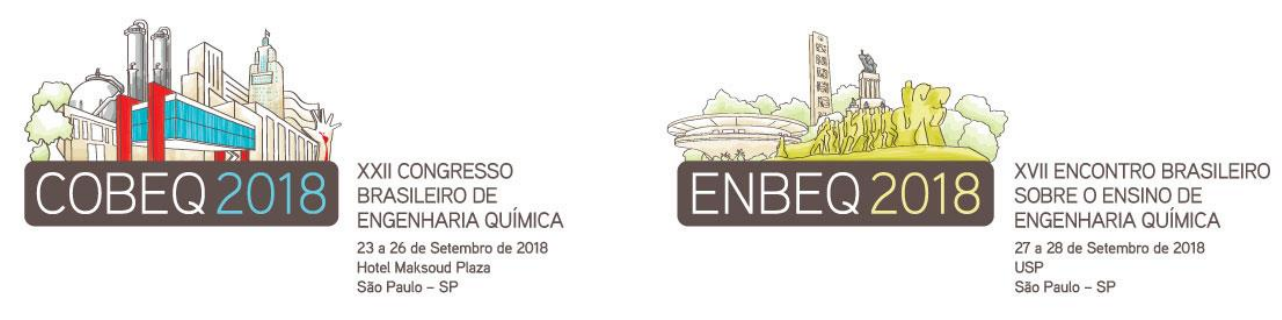

\title{
IMOBILIZAÇÃO DE LIPASE DE Aspergillus niger C EM NANOPARTICULAS MAGNÉTICAS DE HIDROXIAPATITA
}

\author{
SANTOS TC ${ }^{1}$, VIANA JS ${ }^{2}$, TERZI SC ${ }^{1}$, PARIS EC ${ }^{3}$, CABRAL LMC $^{1}$, BRIGIDA AIS $^{14^{*}}$ \\ ${ }^{1}$ Embrapa Agroindústria de Alimentos, ${ }^{2}$ Fundação Centro Universitário Estadual da Zona \\ Oeste-UEZO, ${ }^{3}$ Embrapa Instrumentação, ${ }^{4}$ Embrapa Agroindústria Tropical \\ E-mail para contato: ana.iraidy@embrapa.br
}

\begin{abstract}
RESUMO - O presente trabalho teve por objetivo desenvolver um método para imobilizar lipase de Aspergillus niger $C$ em nanopartículas magnéticas de hidroxiapatita e óxido de ferro (1:1). E a caracterização do mesmo também foi realizada. A imobilização foi efetuada por meio de processo adsortivo. A cinética de adsorção mostrou equilíbrio a partir de $4 \mathrm{~h}$ de imobilização para a atividade do derivado, com rendimento máximo em 4 h. $O \mathrm{pH}$ do meio influencio tanto a imobilização quanto a atividade do derivado obtido em $\mathrm{pH}$ 7. E, embora o derivado seja estável a estocagem, este apresenta queda na atividade logo após o primeiro ciclo reacional.
\end{abstract}

\section{INTRODUÇÃO}

O apelo pela implantação de tecnologias verdes, e o desenvolvimento de processos mais limpos, com menor formação de resíduos e subprodutos, fazem-se necessário para o crescimento de setores industriais com sustentabilidade. Dentre o leque de opções de processos mais limpos, a aplicação de processos biocatalisados destacam-se por gerarem menos subprodutos e, por serem executados em condições reacionais mais amenas. Contudo, questões como custos e estabilidade limitam os processos/produtos aos quais os biocatalisadores (enzimas) podem ser aplicados, sendo este um aspecto crítico na implementação de processos enzimáticos (VOLPATO et al., 2011). Ainda, no sentido de diminuir o custo de produção das enzimas, a utilização de técnicas simples de purificação e imobilização com vistas a garantir o processo de estabilização enzimática eficiente, torna-se um fator de extrema importância, uma vez que esta etapa do processo acarreta em grande parte o custo da enzima (CARVALHO et al., 2017). Outro inconveniente que impede o uso massivo de lipases, e algumas outras enzimas, em nível industrial, está relacionado a sua forma solúvel.

Nesta forma muitas enzimas não são suficientemente estáveis nas condições operacionais, podendo perder sua atividade catalítica devido à auto-oxidação, à auto-digestão ou à desnaturação provocada por solventes, por solutos, por outros agentes ou mesmo pelas condições reacionais. Além disso, quando as enzimas estão solúveis em água, sua separação do meio reacional é difícil e, com isso, sua posterior reutilização torna-se economicamente inviável (VOLPATO et al., 2011). Desta forma, este trabalho visa desenvolver um método para imobilizar lipase de Aspergillus niger $\mathrm{C}$ em nanopartículas magnéticas de hidroxiapatita e óxido de ferro $(1: 1)$. 

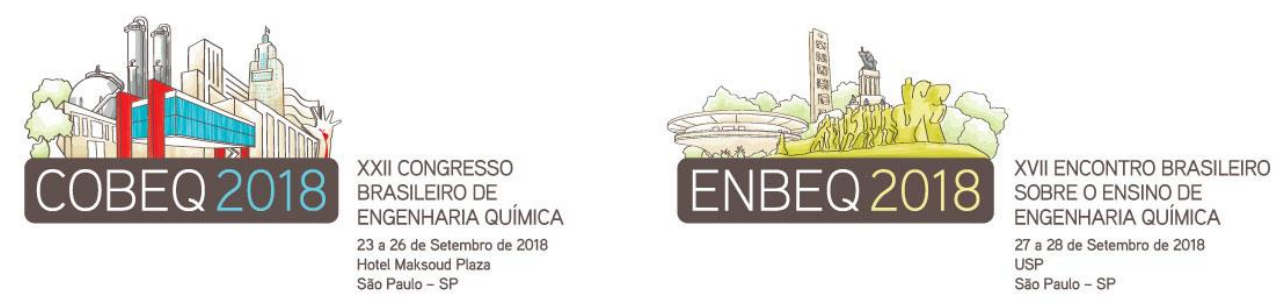

\section{MATERIAIS E METODOS}

\subsection{Produção de lipase e da nanopartícula}

O extrato enzimático lipolítico foi produzido através de fermentação em estado sólido (utilizando torta de dendê como substrato) pelo fungo Aspergillus niger $\mathrm{C}$, isolado em amostras de margarina, da Coleção de Microrganismos de Interesse da Indústria de Alimentos e Agroenergia, da Embrapa Agroindústria de Alimentos. A fermentação foi conduzida em colunas aeradas, incubadas em banho-maria a $32{ }^{\circ} \mathrm{C}$ e com entrada controlada de ar não umedecido de 1,0 vvm por 96 horas. Os fungos foram inoculados em cada coluna contendo $40 \mathrm{~g}$ de meio (torta de dendê umidificada com $80 \mathrm{~mL}$ de solução de sulfato de amônio e com adição de $3 \%$ de borra de dendê como indutor). A enzima foi extraída com a adição de $2,5 \mathrm{~mL}$ de tampão fosfato de sódio ( $\mathrm{pH} 7,0)$ por grama de meio fermentado, permanecendo por 1 hora sob agitação de $90 \mathrm{rpm}$ a $32{ }^{\circ} \mathrm{C}$. O extrato enzimático bruto foi obtido após filtração com papel de filtro seguido de filtração em membrana de microfiltração $(0,45 \mu \mathrm{m})$ para posterior determinação da atividade enzimática.

As nanopartículas utilizadas como suporte foram obtidas em laboratório segundo metodologia descrita em Tavares et al. (2017). As concentrações dos reagentes foram dependentes das relações em massa de hidroxiapatita:magnetita $\left(\mathrm{HA}: \mathrm{Fe}_{3} \mathrm{O}_{4}\right)$ A hidroxiapatita (HAp) com a fórmula Ca10(PO4)6(OH)2, destaca-se como material inorgânico biocompatível importante, e é empregado para a preparação de catalisadores heterogêneos devido a estabilidade estrutural, não toxicidade, grande área de superfície e facilidade de modificação adicional da superfície, como a incorporação de nanopartículas magnéticas de oxido de ferro. Para este trabalho a proporção final do suporte $\mathrm{HA}: \mathrm{Fe}_{3} \mathrm{O}_{4}$ obtido foi de 1:1.

\subsection{Método de Imobilização}

Microtubos plásticos de $2 \mathrm{~mL}$ foram colocados sob agitação rotacional constante de 40 rpm, com $0,007 \mathrm{~g}$ de nanopartícula $\mathrm{HA}: \mathrm{Fe}_{3} \mathrm{O}_{4}(1: 1), 1 \mathrm{~mL}$ de tampão e $0,5 \mathrm{~mL}$ de extrato enzimático bruto. Condições de imobilização como tempo de contato e pH de imobilização foram investigados. Nos pHs 4 e 5 foi utilizado tampão citrato de sódio e nos pHs de 6-9 foram utilizados tampão fosfato de sódio, todas as soluções com molaridade de $20 \mathrm{mM}$. Para o estudo de estabilidade a estocagem, as amostras imobilizadas foram armazenadas a $-10{ }^{\circ} \mathrm{C}$.

\subsection{Atividade enzimática e parâmetros de imobilização}

A reação de hidrólise de p-nitrofenil laurato (pNFL) foi definida como a metodologia padrão para a medida de atividade hidrolítica no presente trabalho. Para tanto, acompanhouse a hidrólise de uma solução de pNFL a $560 \mu \mathrm{M}$ em tampão fosfato de potássio a $50 \mathrm{mM}$ e pH 7. A determinação da concentração de proteínas nos extratos enzimáticos também foi realizada, tendo como padrão a albumina de soro bovino (TAVARES et al., 2017). Rendimento adsortivo foi definido como a medida inicial de atividade da lipase por espectrofotometria ( $\left(\mathrm{At}_{\mathrm{i}}\right)$ e da atividade da enzima final $\left(\mathrm{At}_{\mathrm{f}}\right)$ no sobrenadante, a atividade enzimática remanescente no sobrenadante $\left(\mathrm{At}_{\mathrm{i}}-\mathrm{At}_{\mathrm{f}}\right)$ e o rendimento de imobilização ( $\left.\mathrm{IY}_{\mathrm{imob}}\right)$ puderam ser calculados, utilizando a equação 12 (SOUZA, 2013).

$$
I Y_{i m o b}(\%)=\frac{A t_{i}-A t_{f}}{A t_{i}} * 100
$$



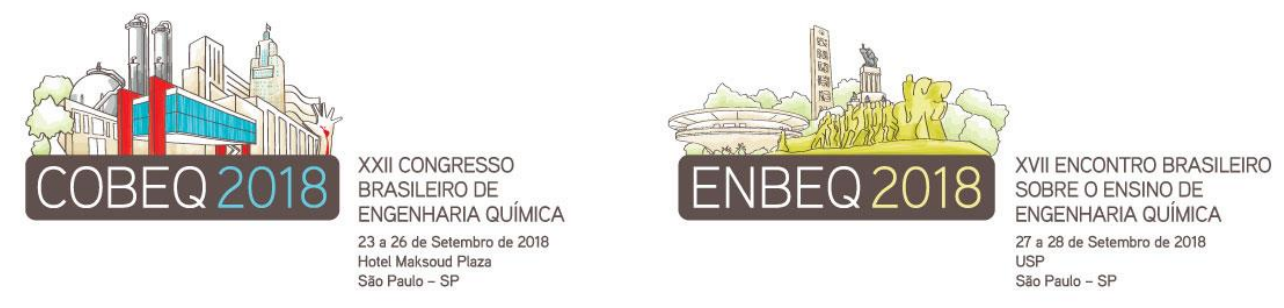

\section{RESULTADOS}

O extrato bruto lipolítico utilizado para os estudos de imobilização apresentou 17,85 $\mathrm{U} / \mathrm{mL}$ e $0,338 \mathrm{mg} / \mathrm{mL}$ de proteína solúvel. O ensaio de cinética de adsorção em pH 7 (Figura 1a) indica que, em 4 horas de contato, alcançou-se um rendimento máximo de $75 \%$ com derivado apresentando 19,7 U/g de atividade enzimática. O sobrenadante contendo a enzima residual foi quantificado com 4,77 U/mL de enzima livre. Após 4 horas de imobilização, o incremento na atividade do derivado foi mínimo, enquadrando-se na faixa de erro experimental.
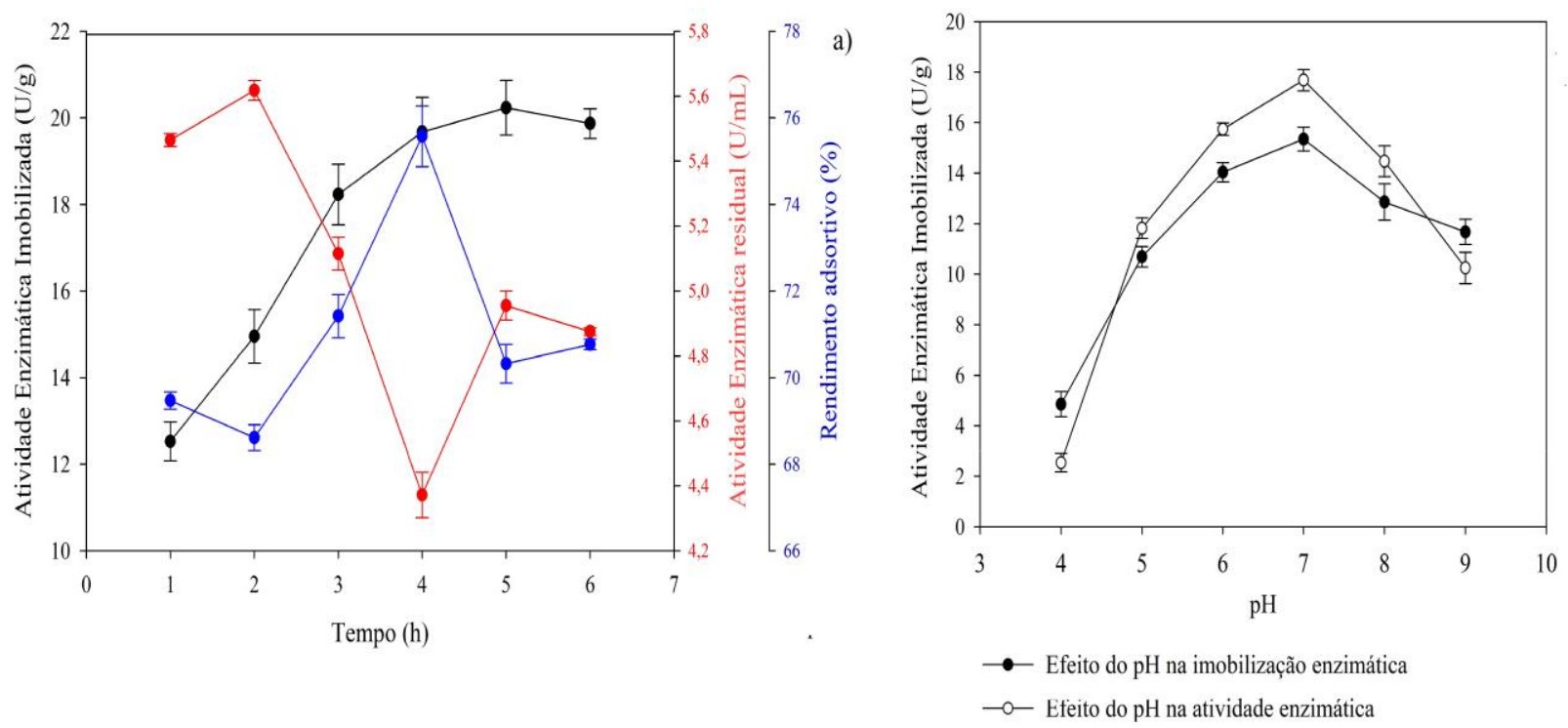

b)

Figura 1 - a) Efeito do tempo de contato sobre a adsorção da lipase em nanopartícula $\mathrm{HA}: \mathrm{Fe}_{3} \mathrm{O}_{4}(1: 1)$; b) Efeito do $\mathrm{pH}$ no processo de adsorção e na atividade enzimática do derivado obtido por adsorção em pH 7.

$\mathrm{O}$ efeito do $\mathrm{pH}$ no processo de adsorção e na atividade enzimática do derivado obtido são apresentados na Figura 1.b. No processo de adsorção, observou-se maior atividade no derivado obtido com $\mathrm{pH}$ de imobilização maior ou igual a 6 . Como o ponto isoelétrico do suporte utilizado é próximo a 2,5 e, como o ponto isoelétrico médio de lipases é próximo de 5 (TAVARES et al., 2017), observou-se maior atividade no derivado quando suporte e enzimas apresentaram cargas de polaridades iguais. E pH ótimo do derivado foi 7, valor semelhante ao do extrato bruto. Um ponto positivo sobre o perfil estudado é que o derivado obtido apresentou atividade enzimática em $\mathrm{pH}$ mais ácidos, o que denota um potencial uso em rotas industriais que requerem $\mathrm{pH}$ mais baixo.

Quando submetido à avaliação da estabilidade operacional, o derivado apresentou perda de $50 \%$ da atividade inicial no terceiro ciclo de reação (Figura 2a). Em relação ao período de armazenagem, a enzima imobilizada em nanopartícula perdeu $24 \%$ da atividade inicial após 1 semana estocada. Até a quarta semana a atividade continuou reduzindo de uma forma mais lenta, de modo que estabilizou após 4 semanas estocada retendo $65 \%$ da atividade 

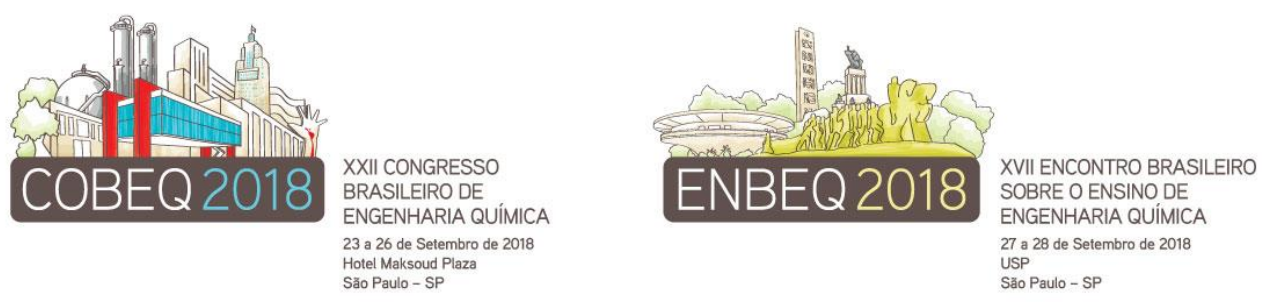

inicial.
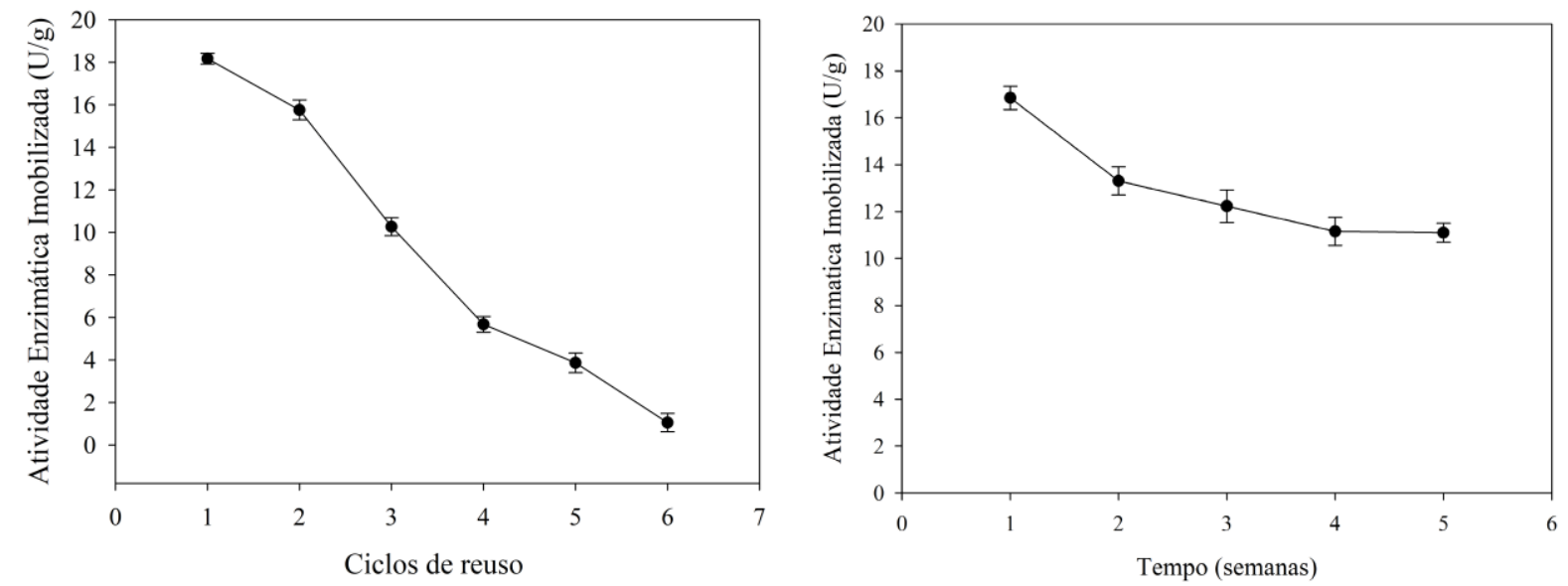

Figura 2 - a) Estabilidade operacional de lipase de Aspergillus niger $\mathrm{C}$ imobilizada em nanopartícula $\mathrm{HA}: \mathrm{Fe}_{3} \mathrm{O}_{4}(1: 1)$; b) Estabilidade a estocagem a $-10^{\circ} \mathrm{C}$.

\section{CONCLUSÃO}

As nanoparticulas de hidroxiapatita e óxido ferro (1:1) possuem potencial como suporte para imobilização de lipase, demostrando resultados positivos em relação a faixa de pH atuante do derivado e à estabilidade a estocagem. Novas estratégias, no entanto, devem ser investigadas para aumentar a estabilidade operacional.

\section{REFERÊNCIAS}

CARVAlHO, T.; FINOTELli, P. V.; BONOMO, R. C. F. ; FRANCO, M. ; AMARAL, P. F. F. . Evaluating Aqueous Two-Phase Systems for Yarrowia lipolytica Extracellular Lipase Purification. Process Biochemistry, v. 52, p. 259-266, 2017.

SOUZA, M. C. M. Imobilização de lipase de Candida antarctica do tipo B em nanopartículas magnéticas visando a aplicação na síntese de ésteres. $88 \mathrm{f}$. Tese de doutorado apresentada ao Programa de Pós-Graduação em Engenharia Química- Universidade Federal do Ceará, Centro de Tecnologia, Departamento de Engenharia Química, Fortaleza - Ceará, 2013.

TAVARES, H. G.; VIANA, J. dos S.; MALAFATTI, J. O. D.; PARIS, E. C.; BRIGIDA, A. I. S. Efeito do pH no processo de imobilização de lipase de thermomyces lanuginosus em HA:FE3O4. In: WORKSHOP DA REDE DE NANOTECNOLOGIA APLICADA AO AGRONEGÓCIO, 9., 2017, São Carlos. Anais ... São Carlos: Embrapa Instrumentação, 2017. p. 239242. Editores: Caue Ribeiro de Oliveira, Elaine Cristina Paris, Luiz Henrique Capparelli Mattoso, Marcelo Porto Bemquerer, Maria Alice Martins, Odílio Benedito Garrido de Assis. 4 p.

VOLPATO, G.; FILICE, M.; RIVAS, B.; RODRIGUES, R. C.; HECK, J. X.; FERNANDEZLAFUENTE, R.; GUISAN, J. M.; MATEO, C.; AYUB, M. A. Z. Purification, immobilization, and characterization of a specific lipase from Staphylococcus warneri EX17 by enzyme fractionating via adsorption on different hydrophobic supports. Biotechnology Progress, v. 27, p. 717-723, 2011. 